\title{
ESTEREOTIPOS LINGÜÍSTICOS EN VILLANCICOS GADITANOS DEL SIGLO XVII
}

\author{
Bruno Camus Bergareche
}

En 1736 el librero Juan de Moya manda imprimir en Madrid una colección de poemas póstumos del valenciano José Pérez de Montoro con el título de Obras pósthumas lyricas sagradas $^{1}$. En la Biblioteca Nacional se conservan los dos volúmenes procedentes de la biblioteca del músico Francisco Barbieri². Pérez de Montoro nació en Játiva en 1627 y murió en 1694 en Cádiz. Fue secretario del rey Carlos II y ejerció como Visitador de las Reales Aduanas del Puerto de Cádiz posiblemente alrededor de diez años. Se conocen diversas obras suyas menores publicadas en Cádiz, Valencia y Sevilla, de naturaleza puramente circunstancial ${ }^{3}$. El grueso de su obra, sin embargo, está constituido por esa colección de obras póstumas editadas por Juan de Moya ${ }^{4}$. El primer volumen y una pequeña parte del segundo están formados básicamente por composiciones profanas que continúan la línea coyuntural y de circunstancias de los textos publicados en vida. La mayor parte del segundo volumen, por el contrario, la componen textos religiosos hechos por encargo con

\footnotetext{
${ }^{1}$ Joseph Pérez de Montoro, Obras posthumas lyricas sagradas, editadas por Juan de Moya, 2 vols. (Madrid, 1736).

2 La obra no es en absoluto una rareza bibliográfica y se encuentra en otras bibliotecas españolas y norteamericanas, v. F. Aguilar Piñal. Bibliografía de autores españoles del siglo XVIII, vol. VI (Madrid, 1991), en el Apéndice, s.v. Moya (Juan de).

${ }^{3}$ Descripción líricojocosa de las reales demostraciones fúnebres y festivas que en la ciudad de Cádiz hizo la nación inglesa a la muerte de su rey Carlos II y la coronación de su sucesor Jacobo Estuardo II (Cádiz, 1685).

Descripción de las fiestas de toros y cañas con que la ciudad de Sevilla y caballeros de la Maestranza festejaron el casamiento del señor Conde de Niebla, primógenito del señor Duque de Medinasidonia (Cádiz, 1687).

Romance jocoserio al Rey nuestro señor Carlos II en la deseada feliz noticia de hallarse en España la Reina nuestra señora Doña Margarita de Neoburg y de Baviera (Valencia, 1690).

Romance endecasilabo al Augustísimo Sacramento del Altar (Sevilla, 1692).

Parabién al Excmo. Sr. Duque de Veragua, Conde de Gelves, en ocasión del feliz nacimiento de su hija Doña Josefa Micaela de Portugal y Ayala (Sevilla, s.a.)

${ }^{4}$ No aparece en N. Antonio, Bibliotheca Hispana Nova (Madrid, 1783-1788). Sí se recoge información sobre Montoro, sin embargo, en J. Rodríguez, Biblioteca Valentina (Valencia, 1747) (hay dos ediciones facsímiles, una, al cuidado de J. Fuster (Valencia, 1977) y la otra, en Librería París-Valencia (Valencia (Valencia, s. a.)), pág. 215; en V. Ximeno, Escritores del Reyno de Valencia, chronologicamente ordenados desde el año 1238 de la christiana conquista de la ciudad, hasta el de 1747, 2 vols. (Valencia, 1747-1749) (ed. facsímil, Valencia, París-Valencia, s. a.), vol. II, págs. 116117; en J. Pastor Fuster, Biblioteca valenciana (Valencia, 1827) (reimpresión, Valencia, París-Valencia, s. a.), pág. 279; y en V. Pascual y Beltrán, Játiva biográfica, 3 vols. (Valencia, Renovación tipográfica, 1931) vol. II, págs. 195-196. De este conjunto de obras procede, sin duda, la información recogida por A. Palau, Manual del librero hispanoamericano (Barcelona, 1948-1977²) vol. XIII, pág. 93. Es en estas fuentes donde hemos obtenido los datos que incluimos.
} 
motivo de diversas festividades religiosas (Navidad y Epifanía sobre todo) celebradas en Cádiz entre 1683 y 1694 . Estas coplas y villancicos destinados a ser cantados en las iglesias gaditanas están presentados y ordenados en bloques, cada uno de ellos correspondiente a las distintas celebraciones y, por tanto, debidamente fechados ${ }^{5}$.

Desde el punto de vista literario, los villancicos de Pérez de Montoro resultan ser un buen ejemplo de las tendencias últimas y más exageradas del Barroco español -comparable con otro autor menor de producción muy similar y contemporáneo suyo, Manuel de León Merchante ${ }^{6}$, de una enorme vacuidad e interesado casi tan sólo por las cuestiones formales, del tipo de los juegos de palabras y los virtuosismos lingüísticos. Trataremos aquí uno de los productos más llamativos de este tipo de preocupaciones: la elaboración cuidadosa de personajes caracterizados por su manera de hablar, auténticos estereotipos lingüísticos.

Efectivamente, el segundo volumen de poemas de Pérez de Montoro contiene un conjunto considerable de villancicos cuyo interés fundamental radica en el origen variadísimo de los personajes que en ellos se presentan. Sin duda, el trabajo que en Cádiz desempeñó Montoro en las aduanas debió de ponerle en contacto con personas procedentes de muy diferentes partes del mundo. Además, seguramente se veía obligado a discutir y charlar con ellos, razón por la cual debió de entrar en contacto con lenguas y modos de hablar español de lo más variopinto. Aprovechando este hecho y el origen probablemente multilingüe del público al que iban destinadas sus composiciones, Montoro gusta de introducir en ellas personajes de procedencia diversa a los que, además, trata de hacer hablar su propia lengua. Excepto en contadas ocasiones, que luego comentaremos, este propósito le obliga, sin duda debido a sus propias limitaciones como conocedor de otros idiomas y, sobre todo, las de su auditorio, a servirse de formas lingüísticas estereotipadas y artificiales en mayor o menor grado en sustitución de las lenguas auténticas.

Así, Montoro da la palabra en sus poemas a negros -o guineos- (hasta en nueve ocasiones), moros o turcos (en dos), gitanos (otras dos), armenios (una), portugueses (tres), asturianos (dos), gallegos (dos), alemanes (dos), catalanes (una), franceses (una), irlandeses (una) y polacos (una), además de otros tipos de modales lingüísticos igualmente curiosos, como tartamudos, sacristanes y pastores.

Como ya decíamos arriba, aunque lo habitual es que el habla sea en todos estos casos una invención del autor, varía notablemente el grado en que cada una de ellas se acerca a la realiadad. Veamos a continuación las características básicas de cada modalidad.

En un caso, en la imitación del habla de los catalanes ${ }^{7}$, la reproducción de la lengua original es absolutamente fiel, como se observa en los versos siguientes:

\footnotetext{
${ }^{5}$ A. Palau, Op. cit., vol. XXVII, págs. 148 y 155, incluye la referencia de algunos villancicos impresos en Cádiz en pliegos sueltos en esas mismas fechas que, sin duda, deben de incluir buena parte de los que escribió Pérez de Montoro y fueron recogidos después por Juan de Moya.

${ }^{6}$ Es también autor de un conjunto de obras de temática variada recogidas póstumamente con el nombre de Obras poéticas pósthumas, divididas en tres clases, sagradas, humanas y cómicas, publicadas en dos volúmenes en Madrid en 1722 y 1733. Vid. A. Palau, Op. cit., vol. VII, pág. 491 y vol. VIII, pág. 187.

${ }^{7}$ Recojo a continuación todos los casos en que Montoro incluye personajes catalanes. Lo mismo haré más abajo al referirme a personajes de otras procedencias: Obras pósthumas... II, pág. 190.
} 
(1)Veniu les miñones

si voleu balar

estes Carnestoltes

porque ya es Nadal:

La faralá, falela, la faralá, laylá.

Yo de Barcelona

li bolgui portar

molts grans que dexi

perque es millor Gra:

La faralá, etc.

Obras pósthumas... II, pág. 190.

La explicación aquí es evidente: Pérez de Montoro, como valenciano que era, conocía perfectamente la lengua.

En otros casos, el habla de los portugueses, asturianos y gallegos ${ }^{8}$, si bien la reproducción está lejos de ser exacta, Montoro se acerca notablemente a la realidad y selecciona rasgos típicos y fácilmente reconocibles de estas lenguas, lo que permite hacerse una idea bastante aproximada de sus características, sobre todo de pronunciación, a finales del siglo XVII, como se muestra a continuación:

(2)Fazaon logar a huas portuguesiñas

para ver au mi Nino das almas e as vidas,

fazaon logar e diranle a mi Nino

que le buscaon as fillas de Mendo e de Brito.

Obras pósthumas... II, pág. 362.

(3)A Turibiong del Parral, guardi Dious, mozong de empeñu,

del Conceyu de Cangas

nostru mayor paroleiro.

Sabei, Turibiong, amigu,

como en todus nuestros puebros

se enbiou a ller vuestra carta

pus que lleer non sabemus.

Obras pósthumas... II, pág. 419.

\footnotetext{
${ }^{8}$ Obras pósthumas... II, págs. 194-195, 341-343 y 362-364; 228-233 y 418-421; 193 y $440-442$ respectivamente.
} 
(4)Ao Reyeciño novo
lo traen de lexas terras
os viellos Reyes cousas
que valen mais que peisan.
Aquel de barba llonga,
con o roupon de seida,
par Deus le dona aquelu
con que afuman a Igreja.

Obras pósthumas... II, pág. 441.

Gracias a estas características, en el caso de variedades mal documentadas en esas fechas, como el asturiano, nos encontramos ante un acontecimiento de gran interés. De hecho, los villancicos de Montoro pueden aportar los primeros testimonios directos de las realizaciones cacuminales de ese dialecto".

El fragmento en que interviene un francés ${ }^{10}$ está a medio camino entre esta reproducción más o menos fiel y la pura invención:

\section{(5)Toca Monsieur}

Al Diu de lis batailes,

Que ao mundo aver veniu,

Toca Monsiur

Al uso de la Fransa

Clarines de bon gust.

$O$ bell, petit Infant,

Garrita mant Iesu,

Si us canta lo fransué,

Per qué plorau ya piu?

Toca Monsiur, etc.

Obras pósthumas... II, pág. 190.

En este tratamiento probablemente influyó un menor conocimiento de esta lengua y quizá también la mayor lejanía respecto al español de la fonética francesa.

Otro grupo distinto lo integran aquellos personajes cuya lengua está completamente inventada. Son los alemanes, irlandeses, polacos y armenios ${ }^{11}$. En los dos primeros casos, dada la inexistencia de un estereotipo previamente fijado, Montoro opta por aplicar un

\footnotetext{
${ }^{9}$ B. Camus, "La pronunciación del portugués del siglo XVII en unos villancicos gaditanos", Verba 19 (1992) 397-407, y "El dialecto asturiano en el siglo XVII", Boletín del Real Instituto de Estudios Asturianos 140 (1992) 375-392.

${ }^{10}$ Obras pósthumas... II, pág. 190.

${ }^{11}$ Obras pósthumas... II, págs. 192 y 201-203; 193; 191; 299-302 respectivamente.
} 
rasgo absolutamente universal en la reproducción de acentos extranjeros: la infinitivización, esto es, los verbos aparecen única y exclusivamente en infinitivo, nunca con formas flexionadas ${ }^{12}$ :

(6)Por qué nacer tan pobre

querer, bello Chiqui,

quando poder tener

por cuna el Potosí?

Padre Morlequín,

Toca de, etc.

Obras pósthumas... II, pág. 192.

(7)Salve, Virge pura,

salve, Filio nato,

que al mundo venisti

pro nostros pecatos.

Salve, etc.

Mas sin tembrar por alegrarlo

he de baylar en Linguo Hispaño

con el gor gor gor del calabazo,

Ay, cómo sabe! ay! ay! ay!

es el gor gor gor del calabazo.

Obras pósthumas... II, pág. 193.

A los polacos se les adjudica una extraña característica: hablan suprimiendo la sílaba final de las palabras. Se trata indudablemente de una invención con fines rítmicos (cf. los versos de cabo roto) y en absoluto obtenida de la observación del habla real:

${ }^{12}$ C. Ferguson, "Absence of Copula and the Notion of Simplicity: A Study of Normal Speech, Baby Talk, Foreigner Talk and Pidgins" en D. Hymes (ed.), Pidginization and Creolization of Languages (Cambridge, 1971) 141-150. 


\begin{abstract}
(8)Con mi papahí
y con una mar

a ver este $\mathrm{Ni}$

me embia el polá.

Ti ti ti ti ti ta,

porque de Poló

esta es la toná.
\end{abstract}

Obras pósthumas... II, pág. 191.

Por último, los armenios hablan como moros y turcos (ver más adelante). Es un tratamiento completamente habitual en la época:

(9)Pues mi, porque hechas de ver

que nino naces hambriento,

li daró por la sustento

uno pocas de café.

Obras pósthumas... II, pág. 301.

A diferencia de este grupo anterior, en el caso de negros, gitanos y moros o turcos existen elaboraciones anteriores del acento de estos hablantes que Montoro retoma sin más añadido. Los gitanos ${ }^{13}$ tienen como rasgo típico el ceceo:

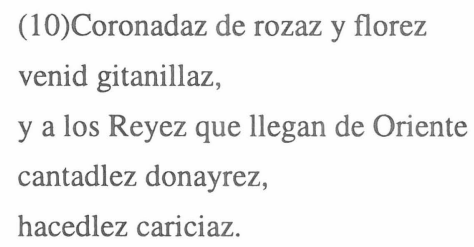

Obras posthumas... II, pág. 432.

A los negros o guineos ${ }^{14}$ se les adjudican rasgos como el yeísmo, la caída de consonantes finales, la confusión de [r]/[1] implosivas, errores en la conjugación de los verbos y en la concordancia, todos ellos ya documentados mucho antes:

(11)Tene, tene, tene, tene,

y que tolo lo mundo cantamo y baylamo,

vamo tocando

passacaye pala e bluto,

\footnotetext{
${ }^{13}$ Obras pósthumas... II, págs. 334-337 y $432-434$.

${ }^{14}$ Obras pósthumas... II, págs. 185-186, 194, 264-267, 284-287, 305-307, 328-331, 347-350, 369-373 y 393-395.
} 
pala los homble viyano,

pala lo albole folía

y pala le aves canalio.

Obras pósthumas... II, pág. 329.

Finalmente, a los moros y sus asimilados $\operatorname{los} \operatorname{tur} \cos ^{15}$ les corresponden los rasgos típicos del habla de moros corriente en el teatro del Siglo de Oro ${ }^{16}$ : infinitivización, despalatalizaciones y errores de concordancia:

(12)Ha Francisquilio? Ha Juanilio?

Antonilio? Qué querer?

Qué querer? Qué mandar?

Ha chiquilios? Ha, ha ha?

Adorar al Corderilio

que Mahoma un lobo estar, ha, ha, ha,

falaylá la la, falaylá, laylá,

andar, andar, yo también andar.

Obras pósthumas... III, pág. 217.

Finalmente, un grupo de elaboraciones lingüísticas originales es el constituido por el habla de los tartamudos ${ }^{17}$, los sacristanes ${ }^{18}$, plagada de latinajos, y los pastores ${ }^{19}$, con rasgos arcaicos como la palatalización de [1] inicial:

(13)Mi mi mire el tartajoso

que de oirte responder

se están nuriendo de risa

la mu mula y el bu buey.

Obras pósthumas... II, pág. 182.

${ }^{15}$ Obras pósthumas... II, págs. 201-203 y 217-219.

${ }^{16}$ A. Sloman, "The Phonology of Moorish Jargon in the Works of Early Spanish Drama and Lope de Vega", Modern Languages Review 44 (1949) 207-217 y B. Camus, "Lingua franca y lengua de moros", Revista de Filología Española 73 (1994) 418-426.

${ }^{17}$ Obras pósthumas... II, págs. 182-185.

${ }^{18}$ Obras pósthumas... II, págs. 252-255.

${ }^{19}$ Obras pósthumas... II, págs. 376-378. 
(14)Porque tantum descalabra

y eris poetarum proterbo,

pues scribantur de verbo

y non dicitur palabra.

Obras pósthumas... II, pág. 253.

(15)Pastora. Este hombre no es mi marido, porque yo estaba en creyente que era un pastor y es un lobo.

Pastor. Llo propio a mí me socede,

pues yo también maginaba

que es moger y es una sierpe.

Obras pósthumas... II, pág. 376.

Existe además un fragmento en el que intervienen personajes perfectamente definidos geográficamente, los toledanos de La Sagra ${ }^{20}$, que, a pesar de que hacen esperar usos lingüísticos diferenciados, no muestran nada especial en este sentido ${ }^{21}$.

De este modo, queda cubierto nuestro propósito inicial de proceder a una descripción general de los elementos de mayor interés lingüístico de los villancicos de Pérez de Montoro. Confiamos en este conjunto de materiales dé pie a futuras investigaciones de mayor calado.

${ }^{20}$ Obras pósthumas... II, págs. 174-176.

${ }^{21}$ Este trabajo ha contado con financiación procedente del fondo de ayuda a la investigación de la Universidad de Castila-La Mancha. Asimismo, es obligado agradecer la colaboración de Luis de Cañigral, sin la cual este trabajo no hubiera sido posible. 


\section{VOLÚMENES ANTERIORES}

(P.V.P. por fascículo: 2.000 ptas. España / 3.000 Extranjero)

\section{VOLUMEN I. AÑO 1986}

(168 págs.)

Mercedes Víchez Díaz: El prólogo del Agemenón de Esquilo como procedimiento literario de anticipación

Juan Collantes de Terán: Noticias para el virreinato de nueva España durante el siglo XVI Jorge Urrutia: La primera crisis del espectáculo cinematográfico y su influencia en el espectáculo teatral

Piedad Bolaños Donoso - Mercedes de los Reyes Peña: Una muestra de la vigencia del teatro español en Portugal durante la primera mitad del siglo XVIII

Catalina Fuentes Rodríguez: Semiótica del Sainete

Juan A. Frago Gracia: Tópicos lingüísticos y tipos cómicos en el teatro y la lírica de los siglos XVI-XVIII

$M^{a}$ Dolores Bermúdez: Análisis del espacio-tiempo de la representación en algunas obras de Eugène Ionesco

Patrice Pavis: le jeu de l'amour et du Hasard dans le téléfilm de Marcel Bluwal

Juan Bargalló: ¿«Nouveau théâtre» o nueva tragedia?

\section{VOLUMEN II. AÑO 1987}

(194 págs.)

Antonio Luque Lozano: Etéocles y Polinices en los símiles de la Tebaida de Estacio

Manuel José Gómez Lara: «O, Never was there queen / So mightly Betray'd'» (I, iii, 24-5):

Locura de amor en Anthony and Cleopatra

Luis Gómez Canseco: Dos notas sobre la religiosidad en la regenta

Clara $M^{a}$ Thomas de Antonio: Hannā Mina: experiencia humana y experiencia literaria

Rosario Guillén Sutil: Cuantificación del superlativo absoluto: muy -ísimo en el habla culta de Sevilla

María Muñoz Romero: Le sentiment de la mort chez Jules Supervielle

Rafael Cano Aguilar: El habla de Sevilla y los dialectalismos del español de América

Concha Fernández Martínez: Sobre la /-s/ final latina

Eva $M^{a}$ Bravo García: Lenguas indígenas y problemas de contacto linguiístico en las relaciones geográficas del siglo XVI

Carmen Arias Abellán: Los tratadistas de agricultura y las Geórgicas de Virgilio. Coincidencias léxicas

María Dolores Gordón Peral: De toponimia hispalense

Fátima Roldán Castro: Los mayūs. A propósito de un texto atribuido a al-Udri

Rafael Valencia: La pervivencia de la tā marbūta por construcción en idāfa en la toponimia medieval sevillana de origen árabe

Catalina Fuentes Rodríguez: El funcionamiento del adverbio y la superación de los límites oracionales

Máximo Brioso Sánchez: Un símil homérico muy debatido: Ilíada XVI 364 ss. 


\section{VOLUMEN III. AÑO 1988 \\ (202 págs.)}

Fátima Roldán Castro - Rafael Valencia Rodríguez: El género al-masālik wa-l-mamālik: su realización en los textos de Al-Udrị y Al-Qazwinin sobre el occidente de Al-Andalus Clara $M^{a}$ Thomas de Antonio: Las técnicas narrativas del novelista sirio Hannā Mina Juan A. Frago García: Norma lingüística y artificio literario en La Lozana andaluza Pablo del Barco: La condición femenina como superación de la novela del romanticismo (Rosalía de Castro)

Manuel Marín Jorge: Del texto a la obra literaria. Problemas de enunciación en el discurso de ficción

María Muñoz Romero: Funcionamiento de los deícticos temporales en la narración E.A. Ramos Jurado: Entorno a la formalización del mito como narración Máximo Brioso Sánchez: Técnica y función de un tipo de relato en los himnos «Homéricos» y en los himnos de Calímaco

Carmen de Mora: La búsqueda de un nuevo humanismo en «Motivos de Proteo»

Trinidad Barrera: La trama novelesca y las digresiones en una novela de Ernesto Sabato Bartolomé Segura Ramos: Una manera de sentir: Euclides de Cunha y Gayo C. Tácito Pilar Bellido: De Arniches a Valle-Inclán: «La casa de Dios» Isabel Román: Hacia una delimitación formal del costumbrismo decimonónico $M^{a}$ Luisa Vargas Lagüens: El elemento fantástico en Beowulf: Estructura y significado Juan Montero: La paternidad equívoca y heroica de Bonifacio Reyes en Su único hijo de Clarín

\section{VOLUMEN IV. AÑO 1989. FASCÍCULO I (460 págs.)}

Augusto Roa Bastos: El indigenismo narrativo en el Paraguay Alfonso García Morales: «Silvia» de Julio Cortázar: la búsqueda de una «Realidad otra» Mercedes Rivas: La escritura paródica de Plan de Evasión y Dormir al sol de Adolfo Bioy Casares

Trinidad Barrera López: El campesinado argentino en la novela de Güiraldes, Don Segundo Sombra (1926)

Gema Areta Marigó: Los espacios sincrónicos de El Mono Gramático

María M. Caballero: León de Greiff en el contexto de la vanguardia colombiana (18951976)

Carmen de Mora: El Llano en llamas o el paisaje desolado de Juan Rulfo

Teodosio Fernández: Sobre el indigenismo en el México posrevolucionario: aportaciones de Gregorio López Y Fuentes

Giuseppe Bellini: Dimensión mítica del indigenismo en Miguel Ángel Asturias

Tomás J. Escajadillo: El indigenismo narrativo peruano

Juan Gil: El establecimiento de la Inquisición en Sevilla y sus consecuencias económicas Antonio Aranda Ortiz: Ejercicios lingüísticos de Antonio Machado 
Juan Montero: Lusitania (1920): un libro olvidado de Rogelio Buendía en la encrucijada ultraísta

José Cebrián: El género épico en España: de los poemas mayores al canto épico.

Alejandro Gómez Camacho: Agustín de Rojas y el Quijote apócrifo

Enrique Jesús Rodríguez Baltanás: ¿Por qué no es una tragedia la Roma Abrasada de Lope de Vega? (Sobre paraliteratura y parodia en Lope)

María José Alonso Seoane: Los últimos días de Diego de León en Nicomedes Pastor Díaz y en Galdós

Aurora Domínguez Guzmán: apuntes para un nuevo diccionario de escritores sevillanos

Rogelio Reyes Cano: La correspondencia entre Prieto Aretino y Cristobal de Castillejo

Pedro M. Piñero - Virtudes Atero: El romancero de Guadalcanal. Un siglo de tradición: de

Micrófilo a hoy

José Manuel Rico García: La epístola de Cetina a don Diego Hurtado de Mendoza

Isabel Román Gutiérrez: Un capítulo de historia de la novela española en el siglo XVIII: lal novela ilustrada de Pedro Montengón

Begoña López Bueno: Las escuelas poéticas españolas en los albores de la historiografía literaria: Arjona y Reinoso

María Luisa Domínguez: Del egotismo barojiano

Marta Palenque: Zorrilla y su concepto del «Tiempo Nuevo» (Lectura de la poesía de sus últimos años)

José María Barrera López: Vida y obra de un vanguardista olvidado: Luis Mosquera (1890-1955)

Luis Gómez Canseco: Individualidad y religión en el Paraíso Cerrado de Pedro Soto de Rojas

Mercedes Comellas Aguirrezábal: Notas sobre el moralismo misógino en el «Diálogo de Mujeres» de Cristóbal de Castillejo

Rafael Morales Astola: Río-Mar-Desierto: Clave / Anticlave

Manuel Bernal Rodríguez: La biblioteca de Juan de Mal Lara

Jorge Urrutia: Estructura de la significación en Los empeños de una casa de Sor Juana Inés de la Cruz

Ángel Luis Acosta Romero: El Barón, comedia neoclásica. Aproximación a su estructura interna (Notas para el comentario)

Mercedes de los Reyes Peña - Piedad Bolaños Donoso: La reconstrucción del Patio de las Arcas de Lisboa tras el incendio de 1697

\section{VOLUMEN IV. AÑO 1989. FASCÍCULO II (398 págs.)}

Rafael Cano Aguilar: La construcción del idioma en Alfonso X «El Sabio»

Miguel Ropero Núñez: Cantos de Soledades y Cantos por Soleares: análisis filológicos

Fernando Rodríguez-Izquierdo Gavala: La palabra poética en Justo Jorge Padrón

Mariano Franco Figueroa: Notas sobre afronegrismos en documentos americanos del caribe en los siglos XVI y XVII

María Dolores Gordón Peral: Sobre los «Navazos» andaluces 
Manuel Ángel Vázquez Medel: La crítica teatral en el siglo XIX. Crónica de un éxito dramático: El esclavo de su culpa, de Juan Antonio Cavestany

Josefa María Mendoza Abreu: Estudio léxico de un documento medieval castellano: ordenamiento de trabajos y precios

Catalina Fuentes Rodríguez: Toponimia rural sevillana: el caso de Pilas

Carmen Loza Ardilla: El lenguaje como símbolo semántico y emotivo

F.A. García Romero: Estudio sobre Hor. Carm. II.3. La influencia de Epicuro

E.A. Ramos Jurado: El modo de composición del Antro de las ninfas de la Odisea de Porfirio

Leonor E. Molero Alcaraz: Comentario filológico de un epígrafe latino (CLE 960)

Máximo Brioso Sánchez: El personaje del «amigo» en la novela griega antigua. De Jenofonte de Éfeso a Aquiles Tacio

J. Solís: Epitalamio de Bambalión Ms. Colombino 7-1-7 de Francesco Filelfo

Mercedes Vílchez: Elementos formales de los decretos de Proxenía griegos

Clara $M^{a}$ Thomas de Antonio: Francia y el conflicto del Líbano

Eugenia Gálvez: La narrativa egipcia

Fátima Roldán Castro: España en la obra de Abd-Al-Wahhāb Al-Bayāti

$M^{a}$ Dolores López Enamorado: La mujer musulmana tradicional en Bayna-l-Quasrayn de Nayỉb Mahfūz

Manuel Carrera Díaz: Ver otros mundos: de Marco Polo a Benzoni

Miguel Ángel Cuevas: La fortuna de Fernando Pessoa en Italia: del mito al conocimiento (1945-1979)

Jacobo Cortines: Canción CXXVI del cancinero de Petrarca

$M^{a}$ concepción Pérez y Pérez: Construcción y mecánica. Del cuerpo libertino en Sade. Experiencia del deseo.

$M^{a}$ Adelaida Porras Medrano: Un ejemplo de percepción diacrónica del espacio: La Colline Inspirée de Maurice Barrès

María Muñoz Romero: Jules Supervielle, le rêveur attentif

Jean-Paul Goujon - $M^{a}$ del Carmen Camero: Pierre Louÿs y Andalucía: nuevas cartas inéditas

J. Bargalló: El tema del doble en el teatro de Jean Genet

Rafael Portillo - Andrés Pérez: Elementos constitutivos del hecho teatral: hacia una definición teórica

Jesús Díaz García: Carta inédita de un viajero inglés por la Andalucía de 1834

Fernando Toda: Influencia de Laurence Sterne en la literatura hispanoamericana contemporánea

Valeria de Marco: O conto espanhol contemporâneo: fragmentos de historia

Julio Sánchez: Las palabras militares en la obra Sebastian Schertlin von Burtenbach. Aproximación al estudio del léxico del Frühneuhochdeutsch

Asunción Sainz Lerchundi: Der Mond hat Durst de Geno Hartlaub

$M^{a}$ Clara Ubieto Artur: Técnicas narrativas en las novelas de Heinrich Böll

Ángela Gracia Menéndez: La construcción de infinitivo según los fundamentos de la gramática integrativa 


\section{VOLUMEN V. AÑO 1990}

(424 págs.)

José María Barrera López: Poesía Nacionalista en Sevilla, 1936-1939

Fernando Rodríguez-Izquierdo y Gavala: Usos preposicionales en Antigüedades y Principado de la Ilustrísima Ciudad de Sevilla, de Rodrigo Caro (1634)

Pilar Benito Agustín - Ma Teresa García-Perla García - Ma José Mora Sena: «The dividing of pity»: All for Love y la evolución del drama inglés de la restauración

María Muñoz Romero: Operaciones de «Repérage» en el texto literario

$M^{a}$ Concepción Pérez y Pérez: Chateubrian et sa voix d'outre-tombe. Un écho sonore d'Histoire

Carmen Ramírez Gómez: en torno a la Revolución ...

Carmen Camero Pérez: «Amants, heureux amants ...» de V. Larbaud: un ejemplo de monólogo autónomo

Manuel Bruña Cuevas: Sobre la reproducción del discurso

Pedro Carbonero Cano: Configuración sintáctica de los enunciados exclamativos

María Dolores Gordón Peral: De Toponomia Hispalense (Continuación)

Inmaculada Oso Silván: Estudio léxico-semántico del gremio de los panaderos

Eva $M^{a}$ Bravo García: Fórmulas de tratamiento americanas y andaluzas en el S. XVI

Rosario Guillén Sutil: Interrelación lexemático-sintáctica de la unidad lingüística parecer en una actuación concreta: habla urbana culta de Sevilla

Esperanza Rocío Alcaide Lara: Precisiones sobre el concepto de oración

Pedro Cano Ávila: Algunos datos del tratado notarial de Abū 1-Qāsim Ibn Salmūn (m.

767/1366)

José María Piñán San Miguel: Las denominaciones del hecho alemán

Ángela Gracia Menéndez: Las representaciones gráficas: medio para visualizar la estructura de la frase

Fernando Magallanes: Dificultades de aplicación de las primeras investigaciones de la «estética de la recepción» a los cuentos de Grimm

Esperanza Bonilla Martínez - Aurora Domínguez Guzmán: Algunos textos desconocidos del siglo XVII de la Biblioteca Arzobispal de Sevilla

$M^{a}$ teresa Pérez Rodríguez: La «novela política» en Perú: Cambio de guardia de Julio Ramón Ribeyro

Carmen Espejo Cala: Bohemia y Licantropía: intertextualidad de diferencias en un cuento de Bioy Casares

José Ignacio Gallardo Ballesteros: El cuaderno de las tapas azules, «Vita Nuova» de Leopoldo Marechal

Rita Gnutzmann: Eugenio Cambaceres: el perfeccionamiento de un escritor José Antonio Sánchez Zamorano: «El siglo de las luces»: una sonata de Alejo Carpentier Mercedes Rivas: Escritura e ideología en la narrativa antiesclavista cubana

E. A. Ramos Jurado: «Eros y el pajarero»: Bión, fr. XIII Gow

Máximo Brioso: Personaje del amigo en la novela griega antigua: Heliodoro (continuación)

Adrián Huici: «La Prometeida»: dialéctica y paradigma

Bartolomé Segura Ramos: La batalla de Elviña 
Rocío Carande: Mal-Lara y Lepanto: Comentario métrico a los epigramas de la galera real Concepción Fernández Martínez: Cum y dum: convergencias y divergencias

\section{VOLUMEN VI. AÑO 1991 \\ (448 págs.)}

Julia Fernández Cuesta: Diferencias y semejanzas entre algunas exclamaciones en inglés medieval y en inglés moderno.

Ángel Sánchez-Escobar: La función del agua en los cuentos de El llano en llamas de Juan Rulfo

Rafael Cano Aguilar: Sintaxis oracional y construcción del texto en la prosa española del Siglo de Oro

Nicolás Valdés: Sobre la inconclusión del Devulgari eloquentia y la reflexión poética en Dante

$M^{a}$ Concepción Pérez Pérez: A través del cuerpo. Metonimia y ensoñación.

Edith Le Bel: Acerca de la inter'retación en lingüística

Bsrtolomé Segura Ramos: Algo sobre la biografía de Horacio y sus contradicciones

Carmen Arias Abellán: La formación de palabras y la Vis Comica en la obra de Plauto

Fernando Rodríguez-Izquierdo y Gavala: Aspectos de la personalidad de Rufino José Cuervo

Manuel Ariza: Notas lingüísticas sobre la Comedia Thebaida

Mercedes Arriaga Florez: La perspectiva pragmática del texto autobiográfico. Cuando el diario se convierte en autobiografía: Sibilla Aleramo

Luis Gómez Canseco: Un episodio en la recepción del Quijote

Stefan Ruhstaller: Brenes y Guadajoz: nombres de lugar sevillanos de filiación mozárabe

Juan Antonio Pacheco Paniagua: Abd al-Karim Gallāb y la literatura política en el Magreb contemporáneo

Ingrid Bejarano Escanilla: El árabe en la Vergleichende Grammatik de Franz Bopp

María Dolores Gordón Peral: lengua e historia. La contribución de la lingüística al conocimiento de las épocas anteriores a la Reconquista de Alcalá de Guadaira

Manuel Maldonado Alemán: La gran ciudad en las Berlín-Gedichte de Georg Heym. Realidad y visión

Carmelo Vera Saura: Naturaleza y poesía en Sandro Penna

Graziella Spampinato: La poesía de la voz (Andrea Zanzotto de Dietro il paesaggio a Idioma)

Fernando Magalllanes: «Mein Lesebuch»: un nuevo tipo de antología literaria

Marta Palenque: La persistencia clasicista en la poesía decimonónica: Las «coronas» a Manuel José Quintana (1855)

Carmen Espejo Cala: Introducción a una poética bajtiniana de Ernesto Sábato

José María Barrera López: Nuevos textos olvidados de Pedro Salinas en su estancia sevillana

Esperanza Rocío Alcaide Lara: Tópico, Tema y Rema: la estructura inforativa en los titulares periodísticos

Máximo Brioso Sánchez - Manuel Bernal Rodríguez: Tolstoi y A. Machado: «A un olmo seco» 
Julia Laguillo Cadenas: El área léxica de la edad en las ciudades de Sevilla y Méjico D.F. Teresa-G. Sibón Macarro: Aproximación a un estudio sociolingüístico del habla de Ceuta M. Lourdes Carriedo López: Dinamicidad en la poesía de Jules Supervielle. De la metáfora a la metamorfosis

Antonio Villarrubia: La oda XV de Baquílides. Técnica compositiva y notas de lectura Clara $M^{a}$ Thomas de Antonio: Semblanza de Tâhâ Husayn

Leonardo Rivera Recio: El simbolismo del vuelo en la Divina Comedia

Eduardo Varela Bravo: Actualidad del mensaje de «El Español» de Blanco White

\section{VOLUMEN VII. AÑO 1992}

Miguel Ángel de Pineda Pérez, $M^{a}$ del Carmen Piña Duarte, Pedro José Vázquez López: Análisis computacional de la morfología del español

Manuel Ollero Toribio, Miguel ángel de Pineda Pérez: Lengua natural y lenguaje lexicográfico

José María Fernández Vázquez: Jacinto Grau y Karel Kapek. Acercamiento a una relación teatral

María Luisa García Nieto Onrubia: En torno a una octava hernandiana de Perito de Lunas José López Romero: Las fuentes literarias en el siglo XVI. El Diálogo en laude de las mugeresde Juan de Espinosa

Norberto Pérez García: El indolente: una narración de la etapa surrealista de Cernuda

Mercedes Vílchez Díaz: Elementos rituales y formales en la trilogía inacabada de Federico García Lorca

Francisca Noguerol Jiménez: El dictador latinoamericano (aproximación a un arquetipo narrativo)

Carmen Espejo Cala: Borges y los árabes

Emilio G. Ferrín: El Islam de Borges

Pedro Cano Ávila: El jurista sevillano Ibn al-Makwi (s. X-XI)

Juan Antonio Pacheco Paniagua: Sobre la traducción de textos sufíes árabes.

Clara $M^{a}$ Thomas de Antonio: Hasan al-Attar y la literatura egipcia en la primer mitad del siglo XIX

Leonor Merino: La périda de identidad en la obra de Malek Haddad

Dolores Bermúdez Medina, Carmen Camero Pérez: Retratos de mujeres: Jean Lorrain Inmaculada Illanees Ortega: Scarron y sus modelos españoles: de la comedia y la novela Magdalena Padilla García: El marqués d'Olincourt o la alteridad como defensa del yo en un relato del marqués de Sade

Carmen Ramírez Gómez: Crebillon Fils, terra incognita en el panorama literario francés del siglo XVIII

Manuel Bruña Cuevas, María Muñoz Romero: Caracterisation syntactico-enonciative des trois modes du discours rapporte

María Luisa Mora Millán: El adverbe de phrase. Una propuesta de análisis

Gloria Álvarez Benito: Revisión de las gramáticas de casos

Paolo Silvestri: Estilización tipológica y convencionalismo lingüístico en el teatro cómico de Giambattista della Porta. La sátira de la erudición: el lenguaje del pedante 
Nicolás Valdés: El camino narrativo de Boccacio

Luis A. Acosta: La figura del héroe en las literaturas germánica y alemana

$M^{o}$ Clara Ubieto Artur: Realismo mágico en la literatura alemana de inmediata postguerra:

Der Ruf, Der Scorpion, Gruppe 47

José Antonio Moreno Jurado: Tradición y ruptura en la poesía neohelénica

Emilia Ruiz Yamuza: Notas al Lysis

Antonio Villarrubia: Algunas consideraciones en torno al Fr. 14 Snell-Maehler de Baquílides

Stefan Ruhstaller: Una nota sobre el léxico del mozárabe sevillano. El andaluz cambuco "barranco".

Norberto Pérez García: Estudio histórico de la palabra pedante

\section{VOLUMEN VIII. AÑO 1993}

(284 págs)

Adelaida Porras Medrano: La construcción de un nuevo orden en la Histoire Comique des Etats et Empires de la Lune de Cyrano de Bergerac

Catalina Fuentes Rodríguez: Acercamiento a las unidades supraoracionales

Daniel López-Cañete Quiles: Enmiendas del Brocense al texto del Ars Poetica de Horacio Miguel Angel Márquez - Pablo Zambrano: En el principio está el fin: De Heráclito a T.S. Elliot

Isidro Pliego Sánchez - Manuela Escobar Montero: Notas sobre la traducción al español de A River Runs through It de Norman Maclean

Esteban Torre: La conciencia lingüística en el texto científico

Pedro Cano Avila: Jurisprudencia andalusí en el alquiler de viviendas

Francisco José Salguero Lamillar: Los problemas de la referencia: modelos para la interpretación del discurso

Carmen Arias Abellán: Sobre las sustantivaciones de -arius en la obra de Plauto (en el marco de la sustantivación del adjetivo latino en general y de las de dicho sufijo a lo largo de todas las etapas del latín)

Alfonso García Morales: Juan Ramón Jiménez, crítico de José Asunción Silva. Sus anotaciones manuscritas

Jesús Lerate de Castro: Las Tres Sorores de Ramón J. Sender: Teoría y Práctica Literaria del Nuevo Romanticismo

Manuel Ariza: Notas sobre el léxico extremeño

Miguel Nieto Nuño: Los primeros textos de Pedro Antonio de Alarcón

Francisca Noguerol Jiménez: Francisco Ayala y el ensayismo argentino

$M^{a}$ Dolores López Enamorado - Eugenia Gálvez Vázquez: La Guerra de África (1909) en la prensa sevillana

Máximo Brioso Sánchez: Geografía mítica de la Grecia Antigua

Magdalena Padilla García: Concha Pérez ( La femme et le pantin ) o la española como prototipo de la mujer fatal

Luis Gómez Canseco: Luis Cernuda en Nueva Inglaterra

Antonio Villarrubia Medina: Algunas cuestiones sobre la obra de Baquílides 
Rafael López-Campos Bodineau: Consideraciones semánticas acerca del uso del dativo alemán y sus posibles concurrencias con otro tipo de construcciones

Clara $M^{a}$ Thomas de Antonio: Las comunidades libanesas y su incidencia en la problemática actual

\section{VOLUMEN IX. AÑO 1994 \\ (262 págs)}

Fernando Magallanes Latas: En torno a la realidad anglosajona como muestra irregular de la Alemania primitiva

Eloy Navarro Domínguez: El "Museo" de Manuel Machado

Carmelo Vera Saura: La metapoesía de Valerio Magrelli

Leonor Molero Alcaraz: Léxico y configuración semántica en latín: la noción de 'extensionalidad'

Luis A. Acosta: Presupuestos sociohistóricos y literarios de la literatura heroica.

Gema Areta: Los Lectores de Manuel González Prada

Assumpta Camps: Génesis y evolución de un perfill literario (para un estudio de la recepción a partir de los estrenos teatrales)

Alessandra Verde: Tres pantominmas de Ramón Gómez de la Serna (Las Danzas): una lectura

Ángela Gracia Menéndez: La gramática integrativa

Fernando Molina Castillo: Conceptos histórico-críticos preliminares a la propuesta de reforma del melodrama de Esteban de Arteaga

Regla Fernández Garrido: clasificaciones oracionales según la modalidad (ammon. in int. 2,9-3,6 Y 64,29-65,2)

Mercedes Arriaga Flórez: Lectores y destinatarios del texto autobiográfico (Perspectivas actuales de la crítica italiana)

Eva $M^{a}$ Bravo García: Un desconocido vocabulario del siglo XVI (El alfabeto de las mercadurías que se avalían en Panamá)

Rafael Martínez Vázquez: Aoristo ingresivo en griego antiguo

Nicolás Valdés: Sobre la realidad mitificada de Carlo Levi

Máximo Brioso Sánchez: Geografía mítica de la Grecia Antigua II

Ingrid Bejarano Escanilla: Un estudio decimonónico sobre la Mucallaqa de Imru'l-Qays

Angélica Valentinetti Mendi: La traducción de Santaella del Libro de las Maravillas

Ángel Sánchez Escobar: La enseñanza de la composición escrita: un "renacimiento" olvidado de nuestras aulas de inglés

Carmen Castrillo Díaz: Toponimia del Parque Nacional de Soñana y su entorno (hidrónimos)

Rosa García Gutiérrez: La ironía como estrategia narrativa en Tienda de Muñecos de Julio Garmendia. 


\section{VOLUMEN X. AÑO 1995 \\ (285 págs)}

Miguel Ángel Rebollo Torío: Características del lenguaje político: la designación.

$M^{a}$ Teresa Pérez: Espacio dramático y símbolo: una lectura de El campo y El señor Galíndez.

Concepción Alonso del Real: "Sapientiæ nomen individuosum et obscurum" (De amic. VIII, 18).

Manuel Maldonado Alemán: La comunicación lingüístico-textual y el problema de la referencia.

Luis A. Acosta: El experimento narrativo en la obra temprana de Peter Weiss.

Manuel Ariza: Leonesismos y occidentalismos en las lenguas y dialectos de España.

Antonio Villarrubia: Algunas notas sobre los himnos homéricos.

Gema Areta: Sobre construcciones fragmentadas.

$M^{a}$ Ángeles Fernández Contreras: Visión y $\theta \alpha \mu ß \beta_{\zeta}$ en Homero, Quinto de Esmirna y Apolonio de Rodas.

Montserrat Martínez Vázquez: Estructuras fundidas prolépticas del inglés actual.

Francisco J. García Morilla: Aproximación a la teoría literaria de Luis Cernuda: el surrealismo.

$M^{a}$ Luisa Gil Iriarte: El lenguaje de las puertas en Oppiano Licario.

Ángel Sánchez Escobar: Sentence combining en el aula: un instrumento para la adquisición y desarrollo de destreza sintáctica del estudiante de inglés.

Rafael Martínez Vázquez: Tiempo relativo en griego antiguo.

$M^{a}$ Ángeles Toda Iglesia: Entre la esperanza y el recelo: acerca de la teoría del arte en The Marble Faun de Nathaniel Hawthorne.

Ángel Estévez Molinero: La mirada andaluza de Lorca (poeta) en Nueva York.

Fernando Magallanes Latas: Las antologías didácticas en Alemania: una cuestión polémica.

Clara $M^{a}$ Thomas de Antonio: Reflejos literarios de la problemática árabe moderna (del siglo XVIII a la Primera Guerra Mundial).

Fernando Ramos López: Algunas visiones del pasado colonial como eje central en el surgimiento del relato árabe en Marruecos. 


\section{NORMAS DE PUBLICACIÓN}

1. Los originales deberán ser inéditos y no estar aprobados para su publicación por ninguna otra entidad.

2. Los originales recibidos serán examinados por miembros del Consejo de Redacción y/o del Consejo Asesor de la Revista.

3. Durante la corrección de pruebas (que se enviarán al autor sin el original), no se admitirán variaciones significativas ni adiciones al texto. Los autores se comprometen a corregir y enviar las pruebas en un plazo máximo de diez días a partir del día en que las reciban.

4. La publicación de artículos en las revistas de la Universidad de Sevilla no da derecho a remuneración alguna. Los derechos de edición son de la Facultad de Filología de la Universidad de Sevilla y es necesario su permiso para cualquier reproducción. En todo caso, será preciso citar la procedencia en cualquier reproducción parcial o total.

5. Los autores tendrán derecho a veinte separatas de los artículos y tres de las reseñas.

\section{NORMAS DE PRESENTACIÓN}

1. Los originales se enviarán al Secretario de la revista (Facultad de Filología, Departamento de Lengua Española, Lingüística y Teoría de la Literatura, C/ Palos de la Frontera, s/n, 41004 Sevilla). Irán precedidos de una hoja en la que figure el título del trabajo, el nombre del autor (o autores), su dirección y el teléfono y el nombre de la institución a la que pertenece. Asimismo, se hará constar la fecha de envío del trabajo.

2. Los artículos y notas tendrán una extensión máxima de veinticinco y ocho páginas respectivamente, a razón de treinta líneas por página y setenta caracteres por línea como máximo. Las reseñas tendrán una extensión máxima de tres páginas. El autor especificará si presenta el trabajo en calidad de artículo o de nota. En todo caso, el Consejo de Redacción se reserva el derecho de proponer al autor la inclusión de su trabajo en una sección distinta de la indicada.

3. Se ha de enviar dos copias impresas de cada manuscrito. Debe adjuntarse una copia del documento original en soporte informático, indicando en la portada del disco el nombre y versión de la aplicación que creó el documento. Pueden enviarse ficheros creados con las aplicaciones siguientes: WORDPERFECT, MS WORD, LOTUS AMIPRO o WORDPRO'97, todas ellas en versión MacIntosh o MS-DOS, pero sólo se aceptarán disquetes de 3'5 pulgadas formateados en sistema MS-DOS para PC. Los ficheros de texto ASCII también son aceptados, debiendo llevar las notas a pie de página enumeradas consecutivamente al final del trabajo.

4. Cada artículo irá acompañado de un resumen de no más de quince líneas (aprox. 250 palabras) redactado en inglés, en hoja aparte (dos copias).

5. Los cuadros, mapas, gráficos, tablas, figuras, etc., que se entreguen con los trabajos deberán ser originales y se presentarán preferentemente en papel vegetal y perfectamente rotulados. Todos irán numerados y llevarán un breve pie o leyenda para su identificación. También se indicará el lugar aproximado de su colocación.

\section{NORMALIZACIÓN DE CITAS Y NOTAS}

1. Los números indicativos de nota serán numerales arábigos, escritos ligeramente por encima de la línea de escritura, e inmediatamente después del material al que se refiere. No irán entre paréntesis.

2. Si la referencia es breve, puede insertarse entre paréntesis en el texto (Ej. Eliot 1920:37), pero la primera referencia completa de un trabajo debe aparecer en una nota o al final del trabajo.

3. Las citas bibliográficas atenderán a las normas siguientes:

LIBROS: INICIAL. APELLIDO DEL AUTOR, TÍTULO (CIUDAD AÑO) PÁGINAS

Ejemplo: T. S. Eliot, The Sacred Wood (London 1920) 36-38.

REVISTAS: INICIAL. APELLIDO DEL AUTOR, "TÍTULO DEL ARTÍCULO", REVISTA N ${ }^{\circ}$ (AÑO) PÁGINAS

Ejemplo: A. Díaz Tejera, "El género en griego clásico: descripción sincrónica y explicación diacrónica", Revista Española de Lingüística 11 (1981) 13-31. 
